\title{
Establishment of Cephalometric Norms for UCLP Cases from Central India Population Falling Under Goslon 1 and 2 Based on Burstone Analysis
}

\author{
Meenakshi M. Tiwari ${ }^{1}$, Pallavi S. Daigavane², Ranjit Kamble ${ }^{3}$, \\ Sunita Shrivastav ${ }^{4}$, Vikrant V. Jadhav ${ }^{5}$, Ramakant M. Tiwari ${ }^{6}$ \\ ${ }^{1}$ Department of Orthodontics, SPDC, Wardha, Maharashtra, India. ${ }^{2}$ Department of Orthodontics, SPDC, \\ Wardha, Maharashtra, India. ${ }^{3}$ Department of Orthodontics, SPDC, Wardha, Maharashtra, India. \\ ${ }^{4}$ Department of Orthodontics, SPDC, Wardha, Maharashtra, India. ${ }^{5}$ Department of Orthodontics, SPDC, \\ Wardha, Maharashtra, India. ${ }^{6}$ Department of Orthodontics, SPDC, Wardha, Maharashtra, India.
}

\section{ABSTRACT}

\section{BACKGROUND}

This study was done as there is a need to evaluate separate hard and soft tissue parameters for UCLP as we cannot compare the deformity with normal. A study by Abhilasha Yadav has defined the Burstone norms for class I subjects in Central India as compared to Caucasians. The objective is to derive norms for UCLP itself as the pattern of growth and development of bone, muscle is not normal that can be compared with any population and needs to treated, based on specific norms.

\section{METHODS}

75 cases of UCLP from Central India, with an age range of 18-25 yrs. were selected for the study. The COGS analysis values for Central Indian UCLP cases (falling under GOSLON 1 and 2) was established and compared with class I Caucasians and class I Central Indian subjects. The cephalograms were traced, analysed and interpreted using the landmarks and values established in Burstone analysis (cephalometric analysis for orthognathic surgery). The mean, standard deviation and $\mathrm{Z}$ values were calculated to compare the values between three groups.

\section{RESULTS}

The Central Indian UCLP cases demonstrated decreased anterior cranial base length, upper third height of face, decreased anteroposterior maxillary length, decreased upper and lower incisor height as well as molar height, retroclined upper anterior, significantly decreased facial convexity, nasolabial angle and reduced maxillary prognathism while mandible showed prognathism.

\section{CONCLUSIONS}

The study reported significant differences in certain cephalometric parameters of UCLP cases from central India population with that of Caucasian and class I central Indian population. The results obtained for central India's UCLP cases can be used as cephalometric norms for planning orthognathic surgery specifically for cleft cases.

\section{KEY WORDS}

UCLP, Burstone Analysis, GOSLON, Central India, Cephalometrics
Corresponding Author: Dr. Meenakshi M. Tiwari, SPDC, Datta Meghe Institute of Medical Sciences, Sawangi, Wardha, Maharashtra, India.

E-mail: drmeenakshigaud@gmail.com

DOI: $10.14260 /$ jemds/2020/297

Financial or Other Competing Interests: None.

\section{How to Cite This Article:}

Tiwari MM, Daigavane PS, Kamble R, et al. Establishment of cephalometric norms for UCLP cases from central india population falling under goslon 1 and 2 based on burstone analysis. J. Evolution Med. Dent. Sci. 2020;9(16):1365-1368, DOI: 10.14260/jemds/2020/297

Submission 10-01-2020,

Peer Review 03-04-2020,

Acceptance 10-04-2020,

Published 20-04-2020. 


\section{BACKGROUND}

Cleft lip and palate patients are generally characterized as possessing abnormalities of dental arch form, malocclusions, facial deformity, and masticatory dysfunction. ${ }^{1}$ These patients require surgical correction in the form of osteotomies or distraction to correct the maxillary defect. One of the principle goals in attaining the facial proportionality is the treatment of dentofacial deformities and this can be achieved with properly designed, planned and performed orthognathic surgical technique. ${ }^{2}$ Diagnosis of any case in orthodontics is incomplete without cephalometrics where for surgical correction numerous analysis are available in the literature. Based on the changing evolutionary patterns many authors have tried to redefine the norms based on population, gender, location etc.

The most challenging task in any diagnostic system is establishment of range of normality. ${ }^{3}$ The standard values of human facial measurements are derived from studies conducted. These standard measurements are utilized to measure the craniofacial dimensions, assessment of facial deformities and to monitor the postoperative results. ${ }^{4}$ Cephalometrics has assisted the clinician in making an accurate diagnosis, treatment planning and evaluating the progress of orthodontic treatment. ${ }^{5}$

A specialized cephalometric appraisal system called cephalometric for orthognathic surgery analysis (COGS) concerning the hard tissue and soft tissue of the face had been developed at the University of Connecticut by Burstone. 5 Many authors have given analysis for better surgical outcome out of which COGS analysis by Burstone stands out to be most successfully. The values derived from COGS analysis proved to be very useful as they are based mostly on linear values not on the angular values, so can be used during planning surgeries, preparing for mock surgery, and can also determine the post-treatment stability. ${ }^{6}$ These analyses have been extensively used for research studies. However, all these studies were carried out in Caucasians based on sample populations of people with EuropeanAmerican ancestries whose reference value may not be applicable to other ethnic types.7,8,9 For this reason, attempts have been made to investigate the differences of the human face among various ethnic groups. ${ }^{10,11}$

Different racial groups should be treated according to their own characteristics and it is therefore important to develop standards for various population groups out of which the craniofacial anomaly stands an odd man out from the normal group and they need a separate norm for the establishment of aesthetically pleasing profile.

The UCLP patients with Goslon 1 and 2 are however towards class I cases but not similar, so the same surgical norms cannot be applied to them. The orthognathic surgery is mostly indicated for GOSLON 4 and 5 and sometimes GOSLON 3. The maxillofacial surgeon from India has been relying on the norms of the Caucasian population. Norms for the Indian population has been not established till date for cleft lip palate patients to guide the maxillofacial surgeons for orthognathic surgery.
So, to establish the norms for unilateral cleft lip palate cases the following study was planned for Central Indian population falling under Goslon 1 and 2 and will be compared with established norms for Caucasian population and class I cases in Central Indian population utilizing the widely accepted analysis given by Burstone et al and Legan.

\section{METHODS}

The Study design is descriptive study Irrespective of age, gender, type of severity, technique of repair and type of growth pattern data of 100 randomly selected, 75 cases of UCLP from Central India, with an age range of 18-25 yrs. were selected for the study UCLP cases were obtained from the Department of Orthodontics and Dentofacial Orthopaedics, Sharad Pawar Dental College, Wardha. (smile train unit). Ethical approval for this study was given by ethical committee of institute and the consent were informed

The selection of patients was based on following criteriaAll cases were non syndromic UCLP, falling under Goslon 1 and 2 with the age group of more than 18 years $^{3}$ Study design is descriptive study. The subjects were above 18 years of age in order to ensure that complete growth had taken place so that variability, because of growth could be avoided.7,8 For all the selected samples lateral cephalogram were evaluated. Manual tracing of radiograph was done on lead acetate tracing sheets. Both hard and soft tissue landmarks were identified and analysed according to the definitions used by Burstone and Legan. 4,5

\section{Statistical Analysis}

The statistical analysis was done using version 15.0 SPSS and probability $\mathrm{z}$ value was calculated. The $\mathrm{Z}$ value other than 0 was considered statistically significant. A $\mathrm{z}$ value is the number of standard deviations from the mean value of the reference population (a population whose known values have been recorded). The $\mathrm{Z}$ value is numerical measurement used in statistics of a value relationship to the mean to a group of values measured in terms of standard deviation from mean.

Various angular and linear measurements for hard and soft tissues in both males and females are_tabulated. All readings obtained were_subjected to statistical analysis for calculating mean and_standard deviation (SD) for both hard and soft tissues using the following formulae-

\section{Mean $=\Sigma \mathrm{Xi} / \mathrm{n}$}

Where, $\mathrm{Xi}=$ Sum of all observations., and $\mathrm{n}=$ Number of observations.

\section{SD $=\sqrt{\Sigma}\left(\mathrm{Xi} \mathrm{X}^{2}\right) / \mathrm{n}-1$}

Where $\mathrm{Xi}=$ Individual values, $\mathrm{X}=$ Mean and $\mathrm{n}=$ Number of Observations. 


\section{RESULTS}

\begin{tabular}{|c|c|c|c|c|c|}
\hline & \multirow{2}{*}{ Parameters } & \multicolumn{2}{|c|}{ Males } & \multicolumn{2}{|c|}{ Females } \\
\hline & & Mean & S.D. & Mean & S.D. \\
\hline \multirow{3}{*}{$\begin{array}{c}\text { Cranial } \\
\text { base }\end{array}$} & Ar-Ptm & 33.7143 & 2.58482 & 33.7 & 3.0 \\
\hline & Ptm -N & 50.7857 & 6.50655 & 47.2 & 2.6 \\
\hline & N-A-PG & 7.1429 & 3.10972 & 4.2 & 2.1 \\
\hline \multirow{3}{*}{$\begin{array}{l}\text { Horizontal } \\
\text { (Skeletal) }\end{array}$} & $\mathrm{N}-\mathrm{A}$ & 5.9286 & 3.02462 & 3.9 & 2.5 \\
\hline & N-B & 8.7143 & 4.63147 & 6.0 & 4.4 \\
\hline & N-Pg & 7.2857 & 4.53073 & 5.3 & 4.1 \\
\hline \multirow{8}{*}{$\begin{array}{c}\text { Vertical } \\
\text { (Skeletal } \\
\text { and Dental) }\end{array}$} & N-ANS & 48.5000 & 5.00384 & 46.8 & 3.9 \\
\hline & ANS-Gn & 63.4286 & 4.36268 & 56.8 & 3.4 \\
\hline & PNS-N & 48.6429 & 3.31911 & 46.1 & 3.0 \\
\hline & MP-HP & 22.9286 & 5.77081 & 21.6 & 6.0 \\
\hline & 1-NF & 25.5714 & 2.24343 & 23.7 & 2.2 \\
\hline & 1-MP & 36.9286 & 5.63593 & 36.9 & 2.8 \\
\hline & 6-NF & 23.2143 & 4.06067 & 21.1 & 2.1 \\
\hline & 6-MP & 30.8571 & 2.87849 & 27.7 & 1.4 \\
\hline \multirow{5}{*}{$\begin{array}{l}\text { Maxilla - } \\
\text { Mandible }\end{array}$} & PNS-ANS & 45.8571 & 4.31201 & 45.4 & 3.9 \\
\hline & AR-Go & 45.5000 & 5.31688 & 44.6 & 5.9 \\
\hline & Go-Pg & 71.7143 & 3.91110 & 70.6 & 5.1 \\
\hline & $\mathrm{B}-\mathrm{Pg}$ & 9.0000 & 3.78255 & 5.3 & 1.5 \\
\hline & Ar-Go-Gn & 127.2857 & 107.47205 & 119.6 & 4.8 \\
\hline \multirow{3}{*}{ Dental } & OP-HP & 5.5000 & 3.27579 & 6.4 & 3.4 \\
\hline & A-B & 2.2500 & 1.87852 & 2.4 & 1.5 \\
\hline & $1-\mathrm{NF}$ & 99.2143 & 26.04487 & 110.2 & 11.5 \\
\hline \multicolumn{6}{|c|}{ Table 1. Hard Tissue in Cleft Males and Females } \\
\hline \multicolumn{6}{|c|}{$\begin{array}{l}\text { Ar- Articulare, PTM- Pterygomaxillary fissure, N- Nasion, A- Subspinale, B- } \\
\text { Supramentale, Pg- Pogonion, Go- Gonion, Gn- Gnathion, HP- Horizontal plane, MP- } \\
\text { Mandibular plane, OP- Occlusal plane, ANS- Anterior nasal spine, PNS- Posterior } \\
\text { nasal spine, NF- Nasal floor, U1- Long axis of upper incisors, L1- Long axis of lower } \\
\text { incisors, Upper 6- mesiobuccal cusp tip of maxillary 1st molar, Lower 6- } \\
\text { mesiobuccal cusp tip of mandibular 1st molar. }\end{array}$} \\
\hline
\end{tabular}

\begin{tabular}{|cccccc|}
\hline & Parameters & \multicolumn{2}{c|}{ Males } & \multicolumn{2}{c|}{ Females } \\
& & Mean & S.D. & Mean & S.D. \\
& G-Sn-Pg' & 2.71 & 3.1 & 6.21 & 4.2 \\
Facial & G-Sn (llel HP) & 3.71 & 2.6 & 4.07 & 3.5 \\
form & G-Pg' (llel HP) & 5.71 & 3.9 & 5.14 & 3.8 \\
& G-Sn/Sn-Me' (^ HP) & 1.06 & 0.10 & 1.11 & 0.12 \\
& Sn-Gn'-C & 110.07 & 7.9 & 109.57 & 6.8 \\
& Sn-Gn'/C-Gn' & 1.37 & 0.3 & 1.06 & 0.2 \\
& Cm-Sn-Ls & 80.35 & 10.4 & 89.07 & 12.4 \\
& Ls to (Sn-Pg') & 3.39 & 2.1 & 3.92 & 2.5 \\
Lip & Li to (Sn-Pg') & 6.82 & 3.0 & 6.5 & 2.8 \\
position & Si to (Li-Pg') & 3.85 & 2.8 & 3.10 & 2.5 \\
and form & Sn-Stms/Stmi-Me' & 0.36 & 0.1 & 0.42 & 0.09 \\
& (HP) & 2.28 & 1.9 & 2.57 & 2.1 \\
& Stms U1 & 2 & 2.6 & 0.92 & 1.8 \\
\multicolumn{4}{c}{ (stm0-stm1) } & 2 & \\
G- Glabella, Cm- Columella point, Sn- Subnasale, Stms- Stomion superius, Stmi- \\
Stomion inferius, Li- Labrale inferius, Ls- Laberale superius, Si- Mentolabial sulcus, \\
Pg'- Soft tissue pogonion, Gn'- Soft tissue gnathion, Me'-Soft tissue menton, C- \\
Cervical point, HP- Horizontal plane.
\end{tabular}

\begin{tabular}{|ccccc|}
\hline Parameters & $\begin{array}{c}\text { Caucasians } \\
\text { Class I Cases } \\
\text { By Burstone }\end{array}$ & $\begin{array}{c}\text { Central Indian } \\
\text { Population } \\
\text { in Class I } \\
\text { Cases }^{\mathbf{(}(\mathbf{n}=76)}\end{array}$ & $\begin{array}{c}\text { Present } \\
\text { Study In } \\
\text { Cleft Cases } \\
\text { (n=100) }\end{array}$ & $\begin{array}{c}\text { Z } \\
\text { Value }\end{array}$ \\
Ar-Ptm & 37.1 & 38.1 & 33.7 & 3.0 \\
Ptm-N & 52.8 & 55.1 & 47.2 & 2.6 \\
N-A-PG & 3.9 & 3.1 & 4.2 & 2.1 \\
N-A & 0.0 & 1.07 & 3.9 & 2.5 \\
N-B & 5.3 & -4.07 & 6.0 & 4.4 \\
N-Pg & 4.3 & -3.85 & 5.3 & 4.1 \\
N-ANS & 54.7 & 55.72 & 46.8 & 3.9 \\
ANS-Gn & 68.6 & 67.67 & 56.8 & 3.4 \\
PNS-N & 53.9 & 54.78 & 46.1 & 3.0 \\
MP-HP & 23 & 21.98 & 21.6 & 6.0 \\
1-NF & 30.5 & 29.44 & 23.7 & 2.2 \\
1-MP & 45.0 & 43.53 & 36.9 & 2.8 \\
6-NF & 26.2 & 26.36 & 21.1 & 2.1 \\
6-MP & 35.8 & 35.60 & 27.7 & 1.4 \\
PNS-ANS & 57.7 & 58.07 & 45.4 & 3.9 \\
AR-Go & 52 & 55.02 & 44.6 & 5.9 \\
Go-Pg & 83.7 & 84.17 & 70.6 & 5.1 \\
B-Pg & 8.9 & 5.98 & 5.3 & 1.5 \\
Ar-Go-Gn & 119.1 & 121.8 & 119.6 & 4.8 \\
OP-HP & 6.2 & 6.01 & 6.4 & 3.4 \\
A-B & -1.1 & 0.07 & -2.4 & 1.5 \\
1-NF & 111.0 & 116.65 & 110.2 & 11.5 \\
Table 3. Z Value of Hard Tissue in Males for Central Indian Population & & & \\
& & & & \\
\hline
\end{tabular}

\section{DISCUSSION}

The cleft palate and/or lip is one of the most common congenital birth defects affecting the human race. The growth and development of maxilla in patients with cleft lip and palate has been of great concern since a long time. With the invent of newer and successful surgical techniques now a days even surgeons have started considering the growth and aesthetic outcome post surgically. The surgeons try their level best to reduce the amount of fibrous tissues which is known to restrict the maxillary growth three dimentionally. ${ }^{11,12}$

The surgical protocol is planned based on the surgical norms established by Burstone in COGS analysis. But most of the norms had been established for Caucasian population. One norm can be erroneous for any other ethnic group. As there is marked craniofacial difference in different ethnic originals.

Past review of literature reveals that there has been no research done for evaluating and establishing cephalometric norms for surgical planning of UCLP cases for Indian population till date. As India is a large country with five zones- Central, East, West, North, South, the present study was done to evaluate, compare and establish norms for Central Indian UCLP population falling under GOSLON 1 and 2 .

The data of study suggest that the values for class I North Indians, ${ }^{2}$ South Indians, ${ }^{3}$ Central Indians, ${ }^{6}$ East Indians ${ }^{12}$ population is different from Caucasians in several aspects. The Central Indian males demonstrated greater anterior cranial base length and ramal length and a reduced chin depth. The inclination of the upper and lower incisors was also greater. Females demonstrated greater posterior cranial base length, increased upper anterior and posterior facial heights, and an increased maxillary length. Both mandibular body and ramal lengths were increased and there was greater mandibular protrusion and a reduced chin depth. The lower incisors were found to be proclinated.

For the hard tissue values evaluation when males were compared to Caucasian and Central Indian males the results were as follows- decreased anterior cranial base length, upper third height of face, while similar lower third face height as that of central Indians males, decreased anteroposterior maxillary length, decreased upper and lower incisor height as well as molar height. Retroclined upper anterior, gonial angle was same as both the other groups but ramus height and mandibular body length were reduced. The posterior cranial base was similar with Caucasian males but reduced as compared to Central Indian males. (table 1)

On evaluation of soft tissue values for males as compared to Caucasian and Central Indian males there was a significantly decreased facial convexity and nasolabial angle, reduced maxillary prognathism while mandible showed prognathism. Lower lip are protruded while chin sulcus depth was reduced. The value of lower face throat length was similar with that of Central Indians but increased as compared to Caucasians. (table 2)

The hard tissue interpretation for UCLP females showed decreased anterior and posterior cranial base length, upper and lower third height of face, decreased anteroposterior maxillary length, decreased upper and lower incisor height as well as molar height. Retroclined upper anterior, gonial angle 
was same as both the other groups but ramus height and mandibular body length were reduced. Chin showed retrusion while greater mandibular prognathism was seen. (table 1, 3).

On soft tissue evaluation for females showed significantly decreased facial convexity and nasolabial angle, reduced maxillary prognathism while mandible showed prognathism. Lower lip are protruded while chin sulcus depth was reduced. Lower face throat length was increased compared to Caucasians while similar with that of Central Indians. (table 2, 3).

\section{CONCLUSIONS}

Orthognathic surgery for cleft cases should be planned cautiously, as anteroposterior growth is the major problem in cleft patients. The cephalometric norms used for diagnosis and treatment planning belong to normal Caucasian population, so same norms cannot be applied to all races and cases as a standard protocol. In the present study, cephalometric norms for the linear and angular measurements for surgical diagnosis and treatment planning of orthognathic surgery needed for central India's UCLP cases has been established, for its practical implementation in achieving better facial morphology. Hence comprehensive treatment planning can be done based on these norms, so authors suggest its use while charting out plan for UCLP patients undergoing orthognathic surgery for correction of skeletal discrepancies.

\section{REFERENCES}

[1] Chaisrisookumporn N, Stella JP, Epker BN Cephalometric profile evaluations in patients with cleft lip and palate. Oral Surgery, Oral Medicine, Oral
Pathology, Oral Radiology and Endodontology 1995;80(2):137-44.

[2] Trivedi K, Singh S, Shivamurthy DM, et al. Analysis of cephalometrics for orthognathic surgery: determination of norms applicable to Rajasthani population. National Journal of Maxillofacial Surgery 2010;1(2):102-7.

[3] Arunkumar KV, Reddy VV, Tauro DP. Establishment of cephalometric norms for the South Indian (Karnataka) population based on Burstone's analysis. Journal of Maxillofacial and Oral Surgery 2010;9(2):127-33.

[4] Burstone CJ, James RB, Legan H, et al. Cephalometrics for orthognathic surgery. J Oral Surg 1978;36(4):269-77.

[5] Legan HL, Burstone CJ. Soft tissue cephalometric analysis for orthognathic surgery. J Oral Surg 1980;38(10):74451.

[6] Yadav AO, Walia CS, Borle RM, et al. Cephalometric norms for Central Indian population using Burstone and Legan analysis. Ind J Dent Res 2011;22(1):28-33.

[7] Anderson G, Fields HW, Beck M, et al. Development of cephalometric norms using a unified facial and dental approach. Angle Orthod 2006;76(4):612-8.

[8] Burstone CJ. Integumental contour and extension patterns. Angle Orthod 1959;29(2):93-104.

[9] Tikku T, Khanna R, Maurya RP, et al. Cephalometric norms for orthognathic surgery in North Indian population using Nemoceph software. Journal of oral Biology and Craniofacial Research 2014;4(2):94-103.

[10] Phillips JH, Nish I, Daskalogiannakis J. Orthognathic surgery in cleft patients. Plastic and Reconstructive Surgery 2012;129(3):535e-48e.

[11] Ross RB. The clinical implications of facial growth in cleft lip and palate. The Cleft Palate Journal 1970;7(1):37-47.

[12] Kasatwar A, Borle R, Bhola N, et al. Prevalence of congenital cardiac anomalies in patients with cleft lip and palate-its implications in surgical management. Journal of Oral Biology and Craniofacial Research 2018;8(3):241-4. 